\title{
BMJ Open Understanding the full burden of drowning: a retrospective, cross- sectional analysis of fatal and non-fatal drowning in Australia
}

\author{
Amy E Peden, ${ }^{1,2}$ Alison J Mahony, ${ }^{1}$ Paul D Barnsley, ${ }^{1}$ Justin Scarr ${ }^{1}$
}

To cite: Peden AE,

Mahony AJ, Barnsley PD, et al. Understanding the full burden of drowning: a retrospective, cross-sectional analysis of fatal and non-fatal drowning in Australia. BMJ Open 2018;8:e024868. doi:10.1136/ bmjopen-2018-024868

- Prepublication history for this paper is available online. To view these files, please visit the journal online (http://dx.doi. org/10.1136/bmjopen-2018024868).

Received 20 June 2018 Revised 15 0ctober 2018 Accepted 19 October 2018

A) Check for updates

(C) Author(s) (or their employer(s)) 2018. Re-use permitted under CC BY-NC. No commercial re-use. See rights and permissions. Published by BMJ.

${ }^{1}$ Royal Life Saving SocietyAustralia, Broadway, New South Wales, Australia

${ }^{2}$ College of Public Health, Medical and Veterinary

Sciences, James Cook University, Townsville, Queensland, Australia

Correspondence to

Amy E Peden;

apeden@rlssa.org.au

\section{ABSTRACT}

Objectives The epidemiology of fatal drowning is increasingly understood. By contrast, there is relatively little population-level research on non-fatal drowning. This study compares data on fatal and non-fatal drowning in Australia, identifying differences in outcomes to guide identification of the best practice in minimising the lethality of exposure to drowning.

Design A subset of data on fatal unintentional drowning from the Royal Life Saving National Fatal Drowning Database was compared on a like-for-like basis to data on hospital separations sourced from the Australian Institute of Health and Welfare's National Hospital Morbidity Database for the 13-year period 1 July 2002 to 30 June 2015. A restrictive definition was applied to the fatal drowning data to estimate the effect of the more narrow inclusion criteria for the non-fatal data (International Classification of Diseases (ICD) codes W65-74 and first reported cause only). Incidence and ratios of fatal to non-fatal drowning with univariate and $\mathrm{X}^{2}$ analysis are reported and used to calculate case-fatality rates. Setting Australia, 1 July 2002 to 30 June 2015. Participants Unintentional fatal drowning cases and cases of non-fatal drowning resulting in hospital separation.

Results 2272 fatalities and 6158 hospital separations occurred during the study period, a ratio of 1:2.71. Children $0-4$ years $(1: 7.63)$ and swimming pools $(1: 4.35)$ recorded high fatal to non-fatal ratios, whereas drownings among people aged 65-74 years (1:0.92), 75+ years $(1: 0.87)$ and incidents in natural waterways (1:0.94) were more likely to be fatal.

Conclusions This study highlights the extent of the drowning burden when non-fatal incidents are considered, although coding limitations remain. Documenting the full burden of drowning is vital to ensuring that the issue is fully understood and its prevention adequately resourced. Further research examining the severity of non-fatal drowning cases requiring hospitalisation and tracking outcomes of those discharged will provide a more complete picture.

\section{INTRODUCTION}

Understanding the full burden of drowning is vital to resourcing and directing prevention efforts. In 2005, a revised definition

\section{Strengths and limitations of this study}

- This is the first total population national study to examine fatal and non-fatal drowning in Australia.

- Novel datasets containing 13 years of fatal and non-fatal drowning cases were created using coronial data, media reports and hospital separation data, allowing identification of time trends.

- Ratios of fatal to non-fatal drowning in different demographics and circumstances provide a guide to identifying the best practice in response to at-risk groups and areas.

- A restrictive definition was applied to the fatal drowning data to estimate the effect of the more narrow inclusion criteria for the non-fatal data (ICD codes W65-74 and first reported cause only).

- These findings represent Australia and similar studies in other countries are recommended.

acknowledged drowning as a process with three possible outcomes: death, morbidity and no morbidity. ${ }^{1}$ While the epidemiology and risk factors for fatal drowning are increasingly understood, ${ }^{2-4}$ particularly in high-income contexts with death registries, ${ }^{5-7}$ there remains limited literature on the total population incidence of non-fatal drowning.

Existing studies on non-fatal drowning identify young children, ${ }^{8-13}$ people aged 65 years and over, ${ }^{14}$ males, ${ }^{8} 10$ minority ethnicity $^{1012}$ and incidents in natural bodies of water $^{8}$ as being commonly represented in the data. Methods used to collate non-fatal drowning data include school-based surveys, ${ }^{8}$ household surveys, ${ }^{9} 15$ hospital discharge data, ${ }^{10}$ emergency department visits ${ }^{11}$ and injury surveillance systems. ${ }^{14}$

WHO estimates that 372000 lives are lost due to unintentional fatal drowning globally each year. ${ }^{2}$ This number is thought to under-report fatal unintentional drowning due to a narrow definition of drowning, which excludes ICD codes covering boating accidents and situations where drowning is 
identified as a secondary cause. ${ }^{16}$ In Australia, unintentional fatal drowning claims the lives of an average 281 people per year, ${ }^{17}$ with children under five, ${ }^{18}$ males $^{5}$ and river users ${ }^{19}$ over-represented.

There have been several studies at a sub-national level examining non-fatal drowning in Australia. Wallis et al mapped mortality and morbidity rates among children and adolescents $0-19$ years in Queensland, ${ }^{20}$ reporting an overall ratio of 1:10 fatal to non-fatal drownings, with $70 \%$ of drowning events occurring in children aged 0-4 years. A Victorian study reported a ratio of 1:2 fatal to non-fatal drownings, with the highest fatal to non-fatal drowning ratio in children $0-4$ years $(1: 7.6) .^{21}$

To date, there have been no national total population studies comparing the profile of non-fatal drowning to that of fatal. This study aims to compare data on fatal and non-fatal drowning in Australia to identify key ratios, significant differences and inform prevention efforts.

\section{METHODS}

Counts of fatal and non-fatal drowning were obtained and the fatal count was modified to simulate the application of the narrower definition of drowning used to identify non-fatal incidents. The directly comparable datasets were then used to calculate situational fatal to non-fatal incident ratios as a proxy for the lethality of drowning.

\section{Fatal drowning data}

The Royal Life Saving Society - Australia (RLSSA) National Fatal Drowning Database (the Fatal Database) contains all unintentional drowning deaths, regardless of the assigned first reported external cause of mortality. The process for capturing all fatal drowning data in Australia has been published previously. ${ }^{19} 2223$ In brief, data are drawn primarily from the National Coronial Information System. ${ }^{24}$ In addition, other data sources such as year-round monitoring of media, police reports, child death review data, social media and reports from lifesaving clubs are used to create a triangulation method. Data from the Fatal Database were correct as at 19 May 2017. Data for the study period 1 July 2002 to 30 June 2015 were extracted from the Fatal Database for the purposes of analysis.

\section{Non-fatal drowning data}

There is no routine collection of non-fatal drowning data in a manner comparable to the fatal data outlined above. Instead, ICD codes assigned to hospital separations (a process by which an episode of care for an admitted patient ceases) were used to calculate the number of hospitalisations related to non-fatal drowning events. Thirteen years of data were obtained from the Australian Institute of Health and Welfare's (AIHW) National Hospital Morbidity Database (NHMD) ${ }^{25}$ for the study period. This dataset defines 'non-fatal drowning' as all hospital separations where the principal diagnosis was any code in ICD-10-AM Chapter XIX Injury, Poisoning and
Certain Other Consequences of External Causes (S00-T98) and the first reported external cause of morbidity was Accidental Drowning and Submersion (W65-W74) ${ }^{26}$ This is the definition of non-fatal drowning we adopt throughout our analysis. This is a narrower definition of' drowning' than that used to identify fatal incidents, meaning that the two datasets are not directly comparable without the modifications outlined below. Hospitalisations were excluded if the patient died in hospital (to avoid double-counting fatal incidents) or if the patient was transferred from another acute care facility (to avoid double counting the same non-fatal incident).

Data were provided in aggregate format by the AIHW, meaning that individual drowning events could not be distinguished. As such, no identifying data or case histories were available and subgroup analysis could be conducted only in relation to included variables, which were victim's age, sex, location and remoteness classification of incident location. Informed consent was not gained as data were deidentified and aggregated.

\section{Comparing the datasets to calculate fatal to non-fatal ratios}

Non-fatal drowning data were compared with the fatal data covering the same period ${ }^{27}$ for the purpose of calculating ratios of fatal and non-fatal drowning incidents in order to identify changes in lethality of drowning over time. The overall ratio was calculated using all available data, as well as specific ratios related to sex, age, aquatic location and remoteness classification of incident location to enable isolation of groups and situations facing high-lethality drowning risk.

The non-fatal drowning dataset contains only drowning incidents where the first reported external cause of morbidity was Accidental Drowning and Submersion (W65-W74). The Fatal Database contains all unintentional drowning deaths, regardless of the assigned first reported external cause of mortality. A large proportion of drowning deaths are assigned one of these codes (W65-W74); however, some are assigned to other codes, including those relating to Water Transport Accidents (V90V94) and Exposure to Forces of Nature (Victim of Flood, X38) ${ }^{16}$

The fatal drowning dataset used does not allow identification of primary ICD codes, meaning that it is impossible to simply exclude fatal incidents based on the narrow non-fatal definition of drowning. Instead, in order to produce a directly comparable estimate of fatal drowning to contrast to the non-fatal dataset, a case study was conducted by manually obtaining case-by-case ICD data for a four financialyear (July 2007 to June 2011) subset of fatal incidents. This was used to generate a restricted fatal drowning dataset for those four financial years including only fatal drowning cases where the first reported external cause of morbidity was Accidental Drowning and Submersion (W65-W74), ${ }^{16}$ in line with the definition used in collating non-fatal incidents.

The need to perform case-by-case analysis of ICD codes using coronial data meant that this directly comparable fatal drowning dataset was only able to be assembled 
for four financialyears from July 2007 to June 2011, rather than the entire study period. Since narrowly defined fatal drowning could not be directly measured outside the four-year case study period, the overall proportion of fatal incidents meeting the narrow drowning definition was estimated based on the ratio of narrowly to broadly defined fatal drowning observed in the case study period. This approach assumes that the proportion of fatal incidents identified as drowning via primary ICD code is relatively stable through time.

This estimate of the proportion of all fatal drowning likely to be excluded under the narrow definition used for non-fatal incidents, as well as proportions calculated for specific age groups and sex within the four-year case study period was then used to estimate the number of fatal incidents captured by the inclusive RLSSA methodology (which includes secondary causes and additional ICD codes) but which would be excluded under the narrower methodology used to assemble the non-fatal drowning dataset.

This estimated number of fatal drowning incidents in the Fatal Database which comply with the restrictive definition, both overall and by age group and sex, was then used in place of the broader estimate throughout the study to ensure directly comparable estimates of fatal and non-fatal drowning incidents. It should be noted that these narrowly defined fatal counts do not reflect the best practice estimate of fatal incidents and are used only to ensure comparability with available non-fatal data.

Figure 1 summarises the process by which comparable fatal and non-fatal drowning counts were estimated.

\section{Statistical analysis}

Crude drowning incidence rates were calculated using Australian population figures from the Australian Bureau of Statistics ${ }^{28}$ and are presented per 100000 persons. Univariate and $X^{2}$ analysis was undertaken with a $95 \%$ CI $(p<0.05) . X^{2}$ analysis compares children (aged $0-17$ years) with adults (18 years and older) as per Australian legislation. ${ }^{29}$ Non-parametric tests were also performed using the proportional basis of the population as the assumed outcome numbers. ${ }^{30}$ For the comparison between fatal and non-fatal drowning, the hypothesis tested was equal frequencies of each drowning outcome in the population. A Spearman's correlation was calculated to test for the relationship between fatal and non-fatal drowning ratios and age group. Remoteness classifications are based on the Australian Statistical Geography Standard. ${ }^{31}$

\section{Patient and public involvement}

The data used in this study are retrospective and deidentified. In the case of the non-fatal drowning data, they were

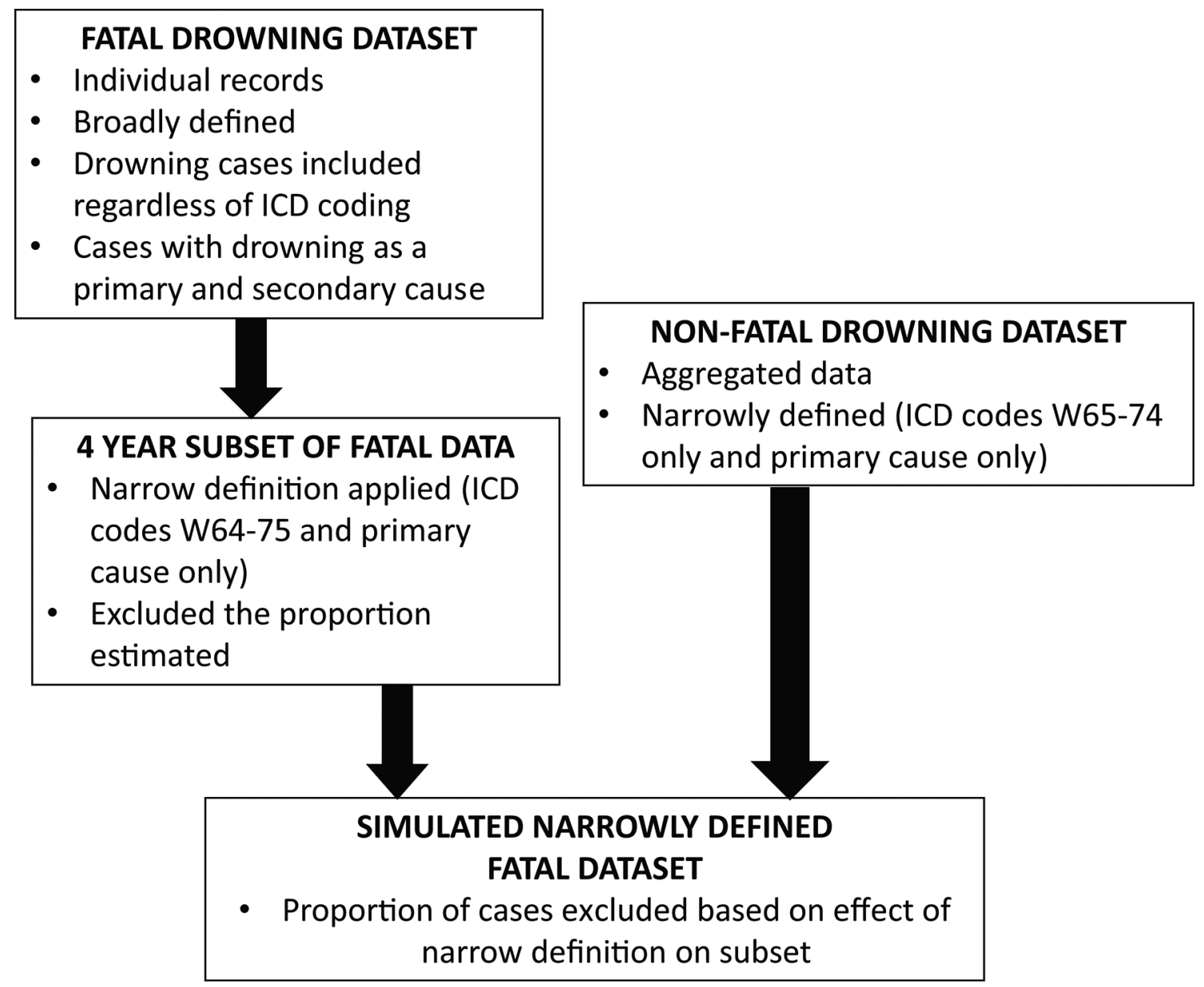

Figure 1 Flow chart depicting methodology used to estimate comparable fatal and non-fatal drowning counts. 




Figure 2 Full burden of unintentional drowning (fatal and non-fatal) and overall incidence by financial year, 2002/2003 to 2014/2015. Fatal figures are estimates of narrowly defined fatal drowning based on assuming constant ratio fatal to non-fatal ratio by age group.

also aggregated to further anonymise the data. In the case of the fatal drowning data, patients were deceased. Therefore, patients were not involved in the study design. Findings will be communicated to the general public through advocacy campaigns to increase awareness of all drowning outcomes (death, morbidity and no morbidity) and how the risk factors differ between fatal and non-fatal drowning.

\section{RESULTS}

\section{Fatal unintentional drowning}

There were 2272 narrowly defined fatal drownings across the study period. Fatal drowning ranged from a high of 196 in 2002/2003 to a low of 157 in 2014/2015. The total crude drowning incidence (both fatal and non-fatal) has been as low as 2.71 per 100000 population in 2011/2012, with the 13-year average crude drowning incidence being 2.99 (all drowning rates are presented per 100000 persons) (figure 2).

Twenty-four per cent $(23.6 \%)$ of those who fatally drowned during the study period were children. Males accounted for $76.9 \%$ of all fatal drownings. Among adults, men were significantly more likely to fatally drown than women, when compared with the sex distribution of child victims $\left(\mathrm{X}^{2}=31.9 ; \mathrm{p}<0.001\right)$ (table 1$)$.

Natural water locations recorded the highest proportion of fatal drownings $(70.5 \%)$. Children were significantly more likely to fatally drown in swimming pools $\left(\mathrm{X}^{2}=317.2 ; \mathrm{p}<0.001\right)$, bathtubs $\left(\mathrm{X}^{2}=10.7 ; \mathrm{p}=0.001\right)$ and locations classified as other/unspecified $\left(\mathrm{X}^{2}=14.6\right.$; $\mathrm{p}<0.001)$ than adults, while adults were significantly more likely than children to fatally drown in natural water locations $\left(\mathrm{X}^{2}=359.7 ; \mathrm{p}<0.001\right)$ (table 1$)$.

Fatal drowning by remoteness classification largely followed population distribution with the largest proportion occurring in areas categorised as major cities $(44.8 \%)$ and the lowest in areas defined as very remote $(4.4 \%)$. Adults were significantly more likely than children to fatally drown in areas classified as remote $\left(\mathrm{X}^{2}=4.9 ; \mathrm{p}=0.027\right)$ (table 1$)$.

\section{Non-fatal unintentional drowning}

There were 6158 hospitalisations due to non-fatal drowning in Australia, a figure that has increased by $42.4 \%$ since the beginning of the study period. Children accounted for $58.0 \%$ of all cases, significantly over-represented when compared with adults $\left(\mathrm{X}^{2}=4190.8 ; \mathrm{p}<0.001\right)$. Males accounted for $66.1 \%$ of all non-fatal incidents, and the over-representation of male victims was significantly greater among adults than in children $\left(\mathrm{X}^{2}=106.8 ; \mathrm{p}<0.001\right)$ (table 2 ).

Eighty-five per cent $(84.5 \%)$ of all non-fatal drowning incidents in swimming pools occurred among children. The leading location for drowning among adults was natural water $(47.5 \%)$, followed by other/unspecified locations $(38.3 \%)$. Location of non-fatal drowning incident mirrors that of fatal drowning, with children significantly more likely than adults to be hospitalised due to non-fatal drowning in swimming pools $\left(X^{2}=976.4\right.$; $\mathrm{p}<0.001)$ and bathtubs $\left(\mathrm{X}^{2}=288.3 ; \mathrm{p}<0.001\right)$, and adults in natural waters $\left(\mathrm{X}^{2}=1055.0 ; \mathrm{p}<0.001\right)$. Adult non-fatal drowning was more likely to occur in major cities $\left(\mathrm{X}^{2}=6.6\right.$; $\mathrm{p}=0.010)$ and in outer regional locations $\left(\mathrm{X}^{2}=11.9\right.$; $\mathrm{p}=0.001)$ (table 2). 
Table 1 Demographic and drowning incident-related data on estimated corrected fatal unintentional drowning, Australia, $2002 / 2003$ to $2014 / 2015$

\begin{tabular}{|c|c|c|c|c|c|c|c|}
\hline & \multicolumn{2}{|l|}{ Total } & \multicolumn{2}{|c|}{ Child (0-17 years) } & \multicolumn{2}{|c|}{ Adult (18years and older) } & \multirow{2}{*}{$\begin{array}{l}X^{2} \text { comparing children to } \\
\text { adults ( } \mathrm{P} \text { values) }\end{array}$} \\
\hline & $\mathbf{N}$ & $\%$ & $\mathbf{N}$ & $\%$ & $\mathbf{N}$ & $\%$ & \\
\hline Total & 2272 & 100.0 & 535 & 23.6 & 1737 & 76.4 & $0.154(0.695)^{*}$ \\
\hline Male & 1747 & 76.9 & 364 & 20.8 & 1383 & 79.2 & \multirow[t]{2}{*}{$31.853(<0.001)$} \\
\hline Female & 525 & 23.1 & 172 & 32.8 & 353 & 67.2 & \\
\hline Natural water & 1713 & 70.5 & 165 & 9.6 & 1548 & 90.4 & $359.662(<0.001)$ \\
\hline Bathtub & 131 & 5.4 & 40 & 30.3 & 91 & 69.7 & $10.744(0.001)$ \\
\hline Other or unspecified & 84 & 3.5 & 30 & 35.9 & 54 & 64.1 & $14.576(<0.001)$ \\
\hline \multicolumn{8}{|c|}{ Remoteness classification of incident postcode $(n=2126) \dagger$} \\
\hline Major cities & 953 & 44.8 & 185 & 19.4 & 768 & 80.6 & $1.834(0.176)$ \\
\hline Very remote & 94 & 4.4 & 17 & 18.0 & 77 & 82.0 & $0.001(0.985)$ \\
\hline
\end{tabular}

${ }^{*}$ Measures distribution by age group of victims against distribution by age group of Australian population.

†Sample sizes represent estimates of the number of fatal drowning incidents meeting the restrictive ICD code definition. Different approaches to estimating this figure-assuming that the proportion of excluded incidents is constant over age, location or remoteness groups-yield a different estimated sample size. To maintain consistent whole-number fatality counts, total sample size is calculated using the sum of the rounded subgroup estimates.

Fatal to non-fatal unintentional drowning ratios

Comparing cases of non-fatal drowning to the fatal drowning cases, after restricting the fatal dataset to simulate identical inclusion criteria, finds an overall ratio of 2.71 non-fatal drownings for each fatal drowning. This ratio peaks in the $0-4$ years age group $(1: 7.63)$. There is a noticeable decrease in the ratio between the $10-14$ years $(1: 6.43)$ and $15-17$ years age group (1:2.89). The ratio continues to decrease until the 65-74 years $(1: 0.92)$ and $75+$ years $(1: 0.87)$ age groups where fatal drowning is more common. Spearman's correlation shows a significantly negative relationship between the age group of those who drown and the ratio of fatal to non-fatal drowning, with the ratio decreasing as people age $\left(r_{\mathrm{s}}=-0.991, \mathrm{p}<0.001\right)$ (table 3).

Table 2 Demographic and drowning incident-related data on cases of non-fatal drowning requiring hospitalisation, Australia, 2002/2003-2014/2015 ( $n=6158)$



*Measures distribution by age group of victims against distribution by age group of Australian population. 
Table 3 Ratio of fatal to non-fatal unintentional drowning, case fatality rate and incidence by age group, Australia, 2002/2003 to $2014 / 2015$

\begin{tabular}{lllllll}
\hline $\begin{array}{l}\text { Age group } \\
\text { (years) }\end{array}$ & $\begin{array}{l}\text { Non-fatal to } \\
\text { fatal ratio }\end{array}$ & $\begin{array}{l}\text { Case fatality } \\
\text { rate }(\%)\end{array}$ & $\begin{array}{l}\text { Average annual } \\
\text { fatal incidence }\end{array}$ & $\begin{array}{l}\text { Average annual } \\
\text { non-fatal incidence }\end{array}$ & $\begin{array}{l}\text { Spearman's } \\
\text { correlation }\end{array}$ & P values \\
\hline $0-4$ & 7.63 & 12 & 2.01 & 15.33 & -0.991 & $<0.001$ \\
$5-9$ & 6.65 & 13 & 0.40 & 2.68 & & \\
$10-14$ & 6.43 & 13 & 0.27 & 1.71 & \\
$15-17$ & 2.89 & 26 & 0.80 & 2.31 & \\
$18-24$ & 2.44 & 29 & 0.82 & 2.00 & \\
$25-34$ & 1.64 & 38 & 0.82 & 1.34 & \\
$35-44$ & 1.80 & 36 & 0.66 & 1.19 & \\
$45-54$ & 1.59 & 39 & 0.72 & 1.14 & \\
$55-64$ & 1.17 & 46 & 0.90 & 1.06 & \\
$65-74$ & 0.92 & 52 & 1.20 & 1.10 & \\
$75+$ & 0.87 & 53 & 1.36 & 1.18 & \\
Total & 2.71 & 27 & 0.87 & 2.36 & - \\
\hline
\end{tabular}

When examining location of drowning incident, other/unspecified locations recorded the highest fatal to non-fatal ratio (1:22.26), followed by swimming pools (1:4.35) and bathtubs (1:3.75). Drownings in areas classified as natural water were more likely to be fatal, recording a ratio of 1:0.94 (table 4).

When comparing fatal to non-fatal drowning incidents, remote and very remote areas and natural bodies of water demonstrated significantly higher lethality of drowning (ie, a higher ratio of fatal to non-fatal incidents). Lower lethality of drowning was demonstrated among young children, drowning incidents in swimming pools, bathtubs and locations classified as other/unspecified, as well as areas classified as major cities (table 5).

\section{DISCUSSION}

Drowning is increasingly recognised as leading to a range of outcomes, not limited to death. While there is a growing body of literature on non-fatal drowning among children, ${ }^{8} 9111320$ the same cannot be said for adults. Using repeated cross-sectional data from two datasets over a period of 13 years, this study provides the first total population, national-level analysis of fatal drowning

Table 4 Ratio of fatal to non-fatal unintentional drowning and case fatality rate by location of drowning incident, Australia 2002/2003 to 2014/2015

\begin{tabular}{lcl}
\hline Location & $\begin{array}{l}\text { Non-fatal to fatal } \\
\text { ratio }\end{array}$ & $\begin{array}{l}\text { Case fatality } \\
\text { rate (\%) }\end{array}$ \\
\hline Swimming pool & 4.35 & 19 \\
Natural water & 0.94 & 52 \\
Bathtub & 3.75 & 21 \\
Other or unspecified & 22.26 & 4 \\
\hline Total & 2.53 & 28 \\
\hline
\end{tabular}

and hospitalisations as a result of non-fatal drowning in Australia.

Our results show an overall ratio of 2.7 non-fatal incidents for every fatal incident. This is higher than the 1.3:1 ratio observed in the US state of New Jersey in 1991. ${ }^{10}$ A study of 2003 US hospitalisation data estimates a ratio of 7.6:1, but this figure excludes fatal drowning where the victim was pronounced dead prior to their arrival at hospital. ${ }^{13}$ Data from 1973 to 1977 in Hawaii ${ }^{32}$ show a $27 \%$ case fatality rate among children who lost consciousness in water, which approximates a 2.7:1 fatal to non-fatal ratio among children only. Studies directly comparing the full burden of fatal and non-fatal drowning remain relatively rare.

\section{Defining non-fatal drowning}

Consistency in data collection and comparison between studies in non-fatal drowning would be greatly enhanced by a uniform non-fatal drowning criteria. This study used hospital separations (admission and subsequent discharge) as the criteria for non-fatal drowning, based on impact to the survivor and health system, and consistent with existing literature. ${ }^{13}$ Previous studies have used a variety of definitions, including emergency department presentations, ${ }^{11} 14$ incidents attended by paramedics ${ }^{21}$ and self-reported injuries. ${ }^{815}$

Drowning prevention research and advocacy has benefited from a standard definition, ${ }^{1}$ outlining consistent terminology to be used and obsolete terminology to be avoided. Current thinking about non-fatal drowning ranges from drownings averted and self-reported experiences of non-fatal drowning, through to high dependency care through the hospital system. Any non-fatal drowning criteria established must provide for greater categorisation potentially on the basis of severity and have applicability to a variety of data sources. A consensus-based approach through expert opinion could be used to 
Table 5 Fatal and non-fatal drowning cases, $X^{2}$ with 95\% Cl ( $p$ value), Australia, 2002/2003-2014/2015

$\mathrm{X}^{2}$ comparing fatal to non-fatal drowning $(P$

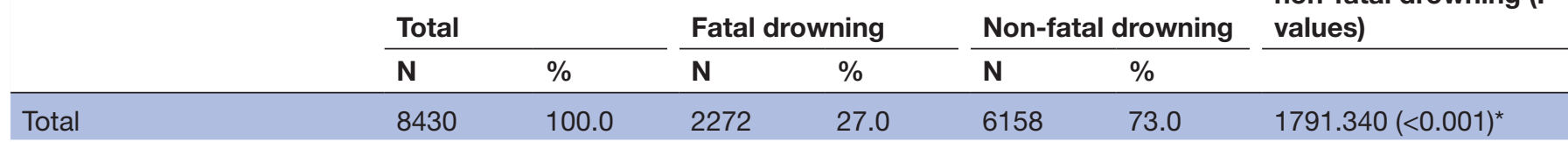

$\operatorname{Sex}(n=8430)$

\begin{tabular}{|c|c|c|c|c|c|c|c|}
\hline Male & 5817 & 69.0 & 1747 & 30.0 & 4070 & 70.0 & $90.503(<0.001)$ \\
\hline Female & 2613 & 31.0 & 525 & 20.1 & 2088 & 79.9 & \\
\hline \multicolumn{8}{|l|}{ Age group $(n=8430)$} \\
\hline Child (0-17 years) & 4108 & 48.7 & 535 & 13.0 & 3573 & 87.0 & \multirow[t]{2}{*}{$789.501(<0.001)$} \\
\hline Adult (18+ years) & 4322 & 51.3 & 1737 & 40.2 & 2585 & 59.8 & \\
\hline \multicolumn{8}{|c|}{ Location of drowning incident $(n=8589) \dagger$} \\
\hline Swimming pool & 2693 & 31.9 & 503 & 18.7 & 2190 & 81.3 & $179.117(<0.001)$ \\
\hline Natural water & 3320 & 39.4 & 1713 & 51.6 & 1607 & 48.4 & $1446.952(<0.001)$ \\
\hline Bathtub & 622 & 7.4 & 131 & 21.1 & 491 & 78.9 & $17.333(<0.001)$ \\
\hline Other or unspecified & 1954 & 23.2 & 84 & 4.3 & 1870 & 95.7 & $718.260(<0.001)$ \\
\hline \multicolumn{8}{|c|}{ Remoteness classification of incident location $(n=7962) \dagger$} \\
\hline Major cities & 4705 & 59.1 & 953 & 20.3 & 3752 & 79.7 & $212.339(<0.001)$ \\
\hline Inner regional & 1630 & 20.5 & 478 & 29.3 & 1152 & 70.7 & $5.211(0.022)$ \\
\hline Outer regional & 1222 & 15.3 & 493 & 40.3 & 729 & 59.7 & $18.569(<0.001)$ \\
\hline Remote & 223 & 2.8 & 108 & 48.4 & 115 & 51.6 & $49.873(<0.001)$ \\
\hline Very remote & 182 & 2.3 & 94 & 51.6 & 88 & 48.4 & $49.748(<0.001)$ \\
\hline
\end{tabular}

${ }^{*}$ Measures distribution by age group of victims against distribution by age group of Australian population.

†As with table 1, fatal sample sizes are estimates based on the application of a correction factor to simulate restrictive counting. Multiple valid correction factors exist, giving differing estimates of fatal drowning when narrowly defined.

ensure relevance for both high-income and low-income and middle-income contexts, as was done in revising the definition of drowning. ${ }^{1}$

\section{These figures understate the true incidence of non-fatal drowning}

In order to ensure accurate ratios of fatal to non-fatal drowning, this study estimated the number of fatal drowning incidents which would have been identified using the unduly restrictive methodology used to identify non-fatal drowning.

A study by Peden et $a l^{16}$ examined the limitations of this narrow definition of drowning using ICD coding. Comparing case capture using W65-74 ICD codes as the primary cause to the more inclusive method employed by RLSSA in its collation of fatal drowning statistics.

Based on these findings, we believe that drowning studies using primary-cause ICD codes significantly understate the true incidence of fatal and non-fatal drowning. We can estimate how much this restrictive approach undercounts drowning by comparing a sample of fatal drowning incidents using the restrictive and inclusive search criteria outlined above. We find that using a restrictive definition of drowning reduces the number of fatal incidents identified by $40.2 \%$ relative to our preferred, more inclusive, definition. The extent to which the definition adopted leads to undercounting varies between demographic groups. ${ }^{16}$ The impact on child drowning, which appear to be consistently categorised by ICD code, is relatively small at $17.3 \%$ for victims $0-4$ years whereas drowning among persons aged $45-54$ is undercounted by $50.6 \%$ when adopting a restrictive definition.

While the results reported in the body of this paper use an undercount of fatal incidents based on the ratio of narrowly to broadly defined incidents between 2007/2008 and 2010/2011, we could instead invert this methodology to estimate the number of non-fatal incidents which would have been discovered using a more inclusive (and more accurate) search criteria.

Assuming the distribution of ICD codes in non-fatal drowning roughly mirrors that for fatal, then accounting for the estimated proportion of non-fatal incidents which are excluded due to the restrictive search criteria used in the NHMD for each age group yields an estimated additional 2934 non-fatal incidents over the study period, for a total of 9092, had the more appropriate search criteria been used.

\section{Children under the age of five}

Children under five have been identified as the age group most at risk of both fatal and non-fatal drowning, accounting for $24 \%$ of the fatal and $58 \%$ of non-fatal 
drowning in this study. The high proportion of non-fatal incidents among this cohort is likely due to close supervision, timely retrieval and effective resuscitation. ${ }^{3334}$ Higher numbers of hospitalisations due to non-fatal drowning in bathtubs and swimming pools in this study are likely linked to this age group and the proximity of bystanders (likely parents and carers) to drowning incidents in and around the home.

With the number of fatal drowning cases in children under five declining, complacency may begin to impact the effectiveness of drowning prevention campaigns and messaging. Non-fatal drowning statistics may prove to be a useful tool to refocus parents and carers' attention on the importance of child drowning prevention strategies $^{35}{ }^{36}$ such as active adult supervision, ${ }^{37} 38$ restricting access to water bodies (including pool fencing) ${ }^{18}$ and timely and effective administration of cardiopulmonary resuscitation. ${ }^{39}$

\section{Fatal drowning more likely among older people and in natural waterways}

Drowning has been identified as a particularly lethal type of injury, ${ }^{15}$ with a lower fatal to non-fatal ratio than motor vehicle traffic occupant deaths and suffocations. ${ }^{11}$ This study found that drowning is more likely to be fatal among older people (aged 65 years and older) and in natural waterways (such as rivers, lakes, beaches and oceans).

Although the broad category of natural waterways makes site-specific analysis challenging, analysis of fatal river drowning data (the leading natural waterway for fatal drowning in Australia) shows increased risk of fatal river drowning in remote and very remote areas that are isolated from major services, including timely medical assistance ${ }^{19}$ Water clarity, currents, debris and limited lifeguard presence also negatively impact quick rescue and retrieval. Flooding ${ }^{40}$ which can impede timely rescue and resuscitation, is also likely to impact survival outcomes.

For older people, the cause is less clear. Previous research showed that $13 \%$ of people aged 65 years and over who fatally drowned in Australia were engaged in an unknown activity prior to drowning. ${ }^{23}$ This is generally taken as a proxy for being alone at the time of drowning, which is likely to impact timely retrieval and resuscitation. Among the same cohort, pre-existing medical conditions were found to be contributory to the drowning in $36 \%$ of cases, which may also impact survival outcomes. With an ageing population globally, ${ }^{41}$ further investigation into factors impacting survival among older people is required. ${ }^{3}$

\section{Implications for prevention}

Understanding the full burden of drowning requires capturing both fatal and non-fatal drowning. Approaches to collecting drowning data which ignore non-fatal drowning are likely to understate the full drowning toll by a factor of three or more, and may prevent the proper allocation of attention and resources to drowning prevention.
The relative lethality of exposure to drowning in different environments and among different groups provides policy-makers with an opportunity to identify groups and locations who currently benefit from the best practice in drowning prevention and to carry those lessons over to at-risk people and places.

One key lesson from the fatal/non-fatal ratios presented here is that the presence of other adults is a key factor in preventing drowning from ending fatally. Children are both disproportionately likely to drown and disproportionately likely to be rescued, likely because they are rarely swimming alone. Likewise, drowning in the home and in urban areas is less lethal than drowning in natural waterways and remote areas, presumably due to the availability of potential rescuers.

\section{Future research}

While this study moves our understanding of the burden of unintentional drowning in Australia forward, there remain knowledge gaps. What is not yet known is the severity of non-fatal drowning on a national level and how this varies by demographics and circumstances. Future research should explore length of stay, time on mechanical ventilation, time in intensive care and victims' longterm outcomes. ${ }^{42}$ Economic and social research should also be conducted quantifying the cost of drowning to the health system and the social impacts (such as mental and emotional health) on the drowning survivor, as well as their loved ones, rescuers and medical personnel. Only when research such as this is undertaken can the full impact of drowning be understood.

\section{Limitations}

This study has limitations. A correction factor is applied to the number of fatal drowning cases to predict the number matching the restrictive definition applied to non-fatal cases, allowing direct comparison between the two. This means that fatal numbers are an estimate of the underlying number of incidents meeting the NHMD drowning definition and are subject to random error. This approach also assumes that the observed proportion of fatal incidents in each age group meeting the restrictive definition of drowning between 2007/2008 and $2010 / 2011$ continued to hold for the remainder of the study period.

The narrow definition of drowning (W65-74 as primary cause only) used to collect non-fatal data and to estimate fatal numbers has been shown to under-report drowning. As a result, while it accurately presents the NHMD estimates, this study likely under-reports the true number of hospital separations due to non-fatal drowning.

\section{CONCLUSION}

Inclusion of non-fatal drowning in drowning totals is vital to understanding the full burden of drowning. This study found 2.7 non-fatal incidents for every fatal drowning, with higher ratios among children under five and in 
swimming pools and bathtubs, indicating that the exclusive use of fatal measures leads to a significant undercount of harmful drowning incidents.

Risk of fatal and non-fatal drowning varies across demographic groups, with children under five making up a disproportionate share of both fatal and non-fatal victims, underlining the need to target parents as well as potential victims in drowning prevention advocacy.

Large variations were observed in the lethality of drowning exposure. Incidents among people aged 65 years and older, in remote areas and in natural waterways, were significantly more likely to be fatal, suggesting that policies encouraging aquatic recreation in the presence of potential rescuers could reduce fatal drowning among these groups.

Research is required to quantify the nature of non-fatal drowning requiring hospitalisation (length of stay, time on ventilation, intensive care requirements) and victim outcomes. The full burden of drowning must be quantified and opportunities to reduce the lethality of drowning exposure identified to ensure that prevention efforts are adequately resourced and effectively targeted at those most at risk.

Acknowledgements The authors would like to acknowledge Surf Life Saving Australia (in particular Shane Daw and Eveline Rijksen) and Sophie Pointer (Flinders University) for their assistance with the sourcing of data and preliminary analysis. Sections of this report are based on data made available by the AlHW. The authors are responsible for the use made of the data in this study. They acknowledge Michael, Jo-ann and Samuel Morris of the Samuel Morris Foundation for their contribution in helping the drowning prevention community to understand the full impact of drowning. They also acknowledge all those who have experienced non-fatal drowning.

Contributors All authors conceptualised the study and approve the submitted manuscript. AEP and AJM sourced the data. AEP and PDB conducted the data analysis. AJM, PDB and JS provided critical analysis of the draft manuscript.

Funding This research is supported by the Royal Life Saving Society-Australia to aid in the reduction of drowning. Research at Royal Life Saving Society—Australia is supported by the Australian Government. The Royal Life Saving National Fatal Drowning Database was developed using funds from the Australian Government and the support of the Australian National Coronial Information System.

Competing interests AEP and AJM were responsible for collating data in the database from the Australian National Coronial Information System.

\section{Patient consent Not required.}

Ethics approval Victorian Department of Justice and Regulation Human Research Ethics Committee (fatal drowning data) (CF/07/13729, CF/10/25057, CF/13/19798) and Children's Health Queensland Ethics Committee (non-fatal drowning data) (HREC/17/QRCH319).

Provenance and peer review Not commissioned; externally peer reviewed.

Data sharing statement Fatal drowning data are available on request; however, as the data are via a third party (coronial data), ethical approval and permission from the data custodians, the Australian National Coronial Information System (NCIS) is required before the authors are able to provide their dataset to the person inquiring. There are strict ethical restrictions around use of these data and it can therefore not be sent to a public repository. Once ethical approval and permission from the NCIS as data custodians have been achieved, researchers can contact ncis@ncis.org.au to gain access to the data. Access to non-fatal drowning data can be sought by completing a data request through the Australian Institute of Health and Welfare using the following website https://www.aihw.gov.au/our-services/ data-on-request.

Open access This is an open access article distributed in accordance with the Creative Commons Attribution Non Commercial (CC BY-NC 4.0) license, which permits others to distribute, remix, adapt, build upon this work non-commercially, and license their derivative works on different terms, provided the original work is properly cited, appropriate credit is given, any changes made indicated, and the use is non-commercial. See: http://creativecommons.org/licenses/by-nc/4.0/.

\section{REFERENCES}

1. van Beeck EF, Branche CM, Szpilman D, et al. A new definition of drowning: towards documentation and prevention of a global public health problem. Bull World Health Organ 2005;83:853-6.

2. World Health Organization. Global report on drowning: preventing a leading killer. Geneva: World Health Organisation, 2014.

3. Peden AE, Franklin RC, Queiroga AC. Epidemiology, risk factors and strategies for the prevention of global unintentional fatal drowning in people aged 50 years and older: a systematic review. Inj Prev 2018;24:240-7.

4. Peden AE, Franklin RC, Leggat PA. Fatal river drowning: the identification of research gaps through a systematic literature review. Inj Prev 2016;22:202-9.

5. Franklin RC, Scarr JP, Pearn JH. Reducing drowning deaths: the continued challenge of immersion fatalities in Australia. Med J Aust 2010;192:123-6.

6. Clemens $\mathrm{T}$, Tamim $\mathrm{H}$, Rotondi $\mathrm{M}$, et al. A population based study of drowning in Canada. BMC Public Health 2016;16:559.

7. Quan L, Pilkey D, Gomez A, et al. Analysis of paediatric drowning deaths in Washington State using the child death review (CDR) for surveillance: what CDR does and does not tell us about lethal drowning injury. Inj Prev 2011;17:i28-i33.

8. Ma WJ, Nie SP, Xu HF, et al. An analysis of risk factors of non-fatal drowning among children in rural areas of Guangdong Province, China: a case-control study. BMC Public Health 2010;10:156.

9. Linnan M, Anh LV, Cuong PV, et al. Child Mortality and Injury in Asia: Survey Results and Evidence. Florence: UNICEF Innocenti Research Centre, 2007

10. Fife D, Scipio S, Crane GL. Fatal and nonfatal immersion injuries among New Jersey residents. Am J Prev Med 1991;7:189-93.

11. Ballesteros MF, Schieber RA, Gilchrist J, et al. Differential ranking of causes of fatal versus non-fatal injuries among US children. Inj Prev 2003;9:173-6.

12. Irwin CC, Irwin RL, Ryan TD, et al. The legacy of fear: is fear impacting fatal and non-fatal drowning of African American children? J Black Stud 2011;42:561-76.

13. Cohen $\mathrm{RH}$, Matter KC, Sinclair SA, et al. Unintentional pediatric submersion-injury-related hospitalizations in the United States, 2003. Inj Prev 2008;14:131-5.

14. Hu G, Baker SP. Recent increases in fatal and non-fatal injury among people aged 65 years and over in the USA. Inj Prev 2010;16:26-30.

15. Cardona $M$, Joshi $R$, Ivers $R Q$, et al. The burden of fatal and non-fatal injury in rural India. Inj Prev 2008;14:232-7.

16. Peden AE, Franklin RC, Mahony AJ, et al. Using a retrospective cross-sectional study to analyse unintentional fatal drowning in Australia: ICD-10 coding-based methodologies verses actual deaths. BMJ Open 2017;7:e019407.

17. Royal Life Saving Society - Australia. Royal Life Saving National Drowning Report 2017. Sydney: Royal Life Saving Society - Australia, 2017.

18. Franklin RC, Peden AE. Improving pool fencing legislation in Queensland, Australia: attitudes and impact on child drowning fatalities. Int J Environ Res Public Health 2017;14:1450.

19. Peden AE, Franklin RC, Leggat PA. The Hidden Tragedy of Rivers: A Decade of Unintentional Fatal Drowning in Australia. PLoS One 2016;11:e0160709.

20. Wallis BA, Watt K, Franklin RC, et al. Drowning mortality and morbidity rates in children and adolescents 0-19 yrs: a populationbased study in Queensland, Australia. PLoS One 2015;10:e0117948.

21. Matthews BL, Andrew E, Andronaco R, et al. Epidemiology of fatal and non-fatal drowning patients attended by paramedics in Victoria, Australia. Int J Inj Contr Saf Promot 2017;24:303-10.

22. Franklin RC, Pearn JH, Peden AE. Drowning fatalities in childhood: the role of pre-existing medical conditions. Arch Dis Child 2017;102:888-93.

23. Mahony AJ, Peden AE, Franklin RC, et al. Fatal, unintentional drowning in older people: an assessment of the role of preexisting medical conditions. Healthy Aging Research 2017;1:e7.

24. National Coronial Information System. Victorian Institute of Forensic Medicine. 2018 www.ncis.org.au.

25. Australian Government, Australian Institute of Health and Welfare. National hospital morbidity database (NHMD). Australia: Australian Government, Australian Institute of Health and Welfare, 2017. 
26. National Centre for Classification in Health. ICD-10-AM Tabular List of Diseases. Sydney, Australia: National Centre for Classification in Health, 2004

27. Royal Life Saving Society - Australia. National fatal drowning database 2002/03 to 2015/16. Sydney: Royal Life Saving Society Australia, 2016.

28. Australian Bureau of Statistics. 3101.0 - Australian demographic statistics. Australia: Australian Bureau of Statistics, 2017.

29. Australian Law Reform Commission. Seen and heard: priority for children in the legal process (ALRC Report 84): Australian Government. 2015 http://www.alrc.gov.au/publications/18-childrensinvolvement-criminal-justice-processes/age-thresholds-criminaljustice-pro

30. Australian Bureau of Statistics. Australian demographic statistics: Estimated resident population by single year of age. Australia: Australian Bureau of Statistics, 2017.

31. Australian Bureau of Statistics. 1217.0.55.001 - Glossary of statistical geography terminology. Australia: Australian Bureau of Statistics, 2011.

32. Pearn JH, Wong RY, Brown J, et al. Drowning and near-drowning involving children: a five-year total population study from the City and County of Honolulu. Am J Public Health 1979;69:450-4.

33. Kyriacou DN, Arcinue EL, Peek C, et al. Effect of immediate resuscitation on children with submersion injury. Pediatrics 1994;94:137-42.
34. Marchant J, Cheng NG, Lam LT, et al. Bystander basic life support: an important link in the chain of survival for children suffering a drowning or near-drowning episode. Med J Aust 2008;188:484-5.

35. Wallis BA, Watt K, Franklin RC, et al. Interventions associated with drowning prevention in children and adolescents: systematic literature review. Inj Prev 2015;21:195-204.

36. Bugeja L, Franklin RC. An analysis of stratagems to reduce drowning deaths of young children in private swimming pools and spas in Victoria, Australia. Int J Inj Contr Saf Promot 2013;20:282-94.

37. Morrongiello BA, Schell SL. Child injury: the role of supervision in prevention. Am J Lifestyle Med 2010;4:65-74.

38. Peden AE, Franklin RC, Pearn JH. Unintentional fatal child drowning in the bath: A 12-year Australian review (2002-2014). J Paediatr Child Health 2018;54:153-9.

39. Tobin JM, Ramos WD, Pu Y, et al. Bystander CPR is associated with improved neurologically favourable survival in cardiac arrest following drowning. Resuscitation 2017;115:39-43.

40. Peden AE, Franklin RC, Leggat $P$, et al. Causal pathways of flood related river drowning deaths in Australia. PLoS Curr 2017;18. Edition

41. Audit Commission. Don't stop me now: preparing for an ageing population. London: Audit Commission, 2008.

42. Pearn J. Neurological and psychometric studies in children surviving freshwater immersion accidents. The Lancet 1977;309:7-9.

43. Manglick MP, Ross FI, Waugh MC, et al. Neurocognitive outcomes in children following immersion: a long-term study. Arch Dis Child 2018;103:784-9. 